\title{
Seasonal variability and geostrophic circulation in the eastern Mediterranean as revealed through a repeated XBT transect
}

\author{
V. Zervakis ${ }^{1}$, G. Papadoniou ${ }^{2}$, C. Tziavos ${ }^{1}$, and A. Lascaratos ${ }^{2}$ \\ ${ }^{1}$ National Center for Marine Research, Aghios Kosmas, GR-16 604 Hellenikon, Greece \\ ${ }^{2}$ University of Athens, Department of Applied Physics, University Campus, Bldg. Phys-V, GR-15 784 Athens, Greece
}

Received: 2 July 2001 - Revised: 4 July 2002 - Accepted: 11 July 2002

\begin{abstract}
The evolution of the upper thermocline on a section across the eastern Mediterranean was recorded biweekly through a series of XBT transects from Piraeus, Greece to Alexandria, Egypt, extending from October 1999 to October 2000 on board Voluntary Observing Ships in the framework of the Mediterranean Forecasting System Pilot Project. The data acquired provided valuable information on the seasonal variability of the upper ocean thermal structure at three different regions of the eastern Mediterranean: the Myrtoan, Cretan and Levantine Seas. Furthermore, the horizontal distance ( $\sim 12$ miles) between successive profiles provides enough spatial resolution to analyze mesoscale features, while the temporal distance between successive expeditions ( $2-4$ weeks) allows us to study their evolution. Subbasin scale features are identified using contemporaneous sea surface temperature satellite images. The cross-transect geostrophic velocity field and corresponding volume fluxes for several sub-basin scale features of the Levantine Sea are estimated by exploiting monthly $\theta / S$ diagrams from operational runs of the Princeton Ocean Model in use at NCMR. A southwestward transport in the proximity of the southeast tip of Crete was estimated between 1-3 Sv. The transport increases after the winter formation of dense intermediate water in the Cretan Sea strengthens the pressure gradient across the Cretan Straits. The Mersah-Matruh anticyclone was identified as a closed gyre carrying about $2-6 \mathrm{~Sv}$. This feature was stable throughout the stratified period and disappeared from our records in March 2000. Finally, our data reveal the existence of an eastward-flowing coastal current along the North African coast, transporting a minimum of 1-2 Sv.
\end{abstract}

Key words. Oceanography: physical (eddies and mesoscale processes; currents; marginal and semi-closed seas)

\section{Introduction}

The Mediterranean Forecasting System Pilot Project (MFSPP) was an international effort supported by the 4th Frame-

Correspondence to: V. Zervakis (zervakis@ncmr.gr) work Programme of the European Commission, aiming to develop the main observing and modelling components of an operational forecasting system able to produce weekly to monthly forecasts of ecosystem variability (Pinardi and Flemming, 1998). The project had a strong observational component, consisting of biogeochemical mooring arrays, satellite observations and upper-ocean temperature monitoring through expendable bathythermograph (XBT) deployments from voluntary observing ships (VOS). Observations were transmitted in near-real-time to the operational center of the MFSPP in Italy for assimilation in the numerical models used for the forecasts. The VOS component of the project was designed in a way as to maximize the spatial and temporal coverage of the Mediterranean. Several regular routes of commercial ships (either liners or cargo vessels) were selected, crossing regions of interest in the Mediterranean. The eastern Mediterranean was covered by 4 routes: the Greek National Center for Marine Research (NCMR) was responsible for a transect joining the harbors of Piraeus, Greece and Alexandria, Egypt. This track intersects three seas of the eastern Mediterranean: the northern part of the Myrtoan Sea, extending between mainland Greece and the archipelago of the Cyclades Islands; the eastern part of the Cretan Sea, between the Cyclades and the island of Crete; and the Levantine basin, between Crete and Egypt (Figs. 1a, and b).

Most of the oceanographic knowledge about the latter region was obtained through the project Physical Oceanography of the eastern Mediterranean (POEM) that took place through 1985-1992 (Malanotte-Rizzoli and Robinson, 1988; Robinson et al., 1991). The basic features of the sub-basin scale circulation of the region were then recognized and recorded for the first time. Figure 1a summarizes the subbasin scale circulation of the region as revealed by the POEM project. Past tense will be used in the description of the POEM-revealed circulation of the eastern Mediterranean, as it has proven to be highly variable interannually (MalanotteRizzoli et al., 1999; Hecht and Gertman, 2001). The Ionian Atlantic Stream (IAS), carrying Modified Atlantic Water from the western to the eastern Mediterranean, was found to leave the North African coast and follow a northeastward 


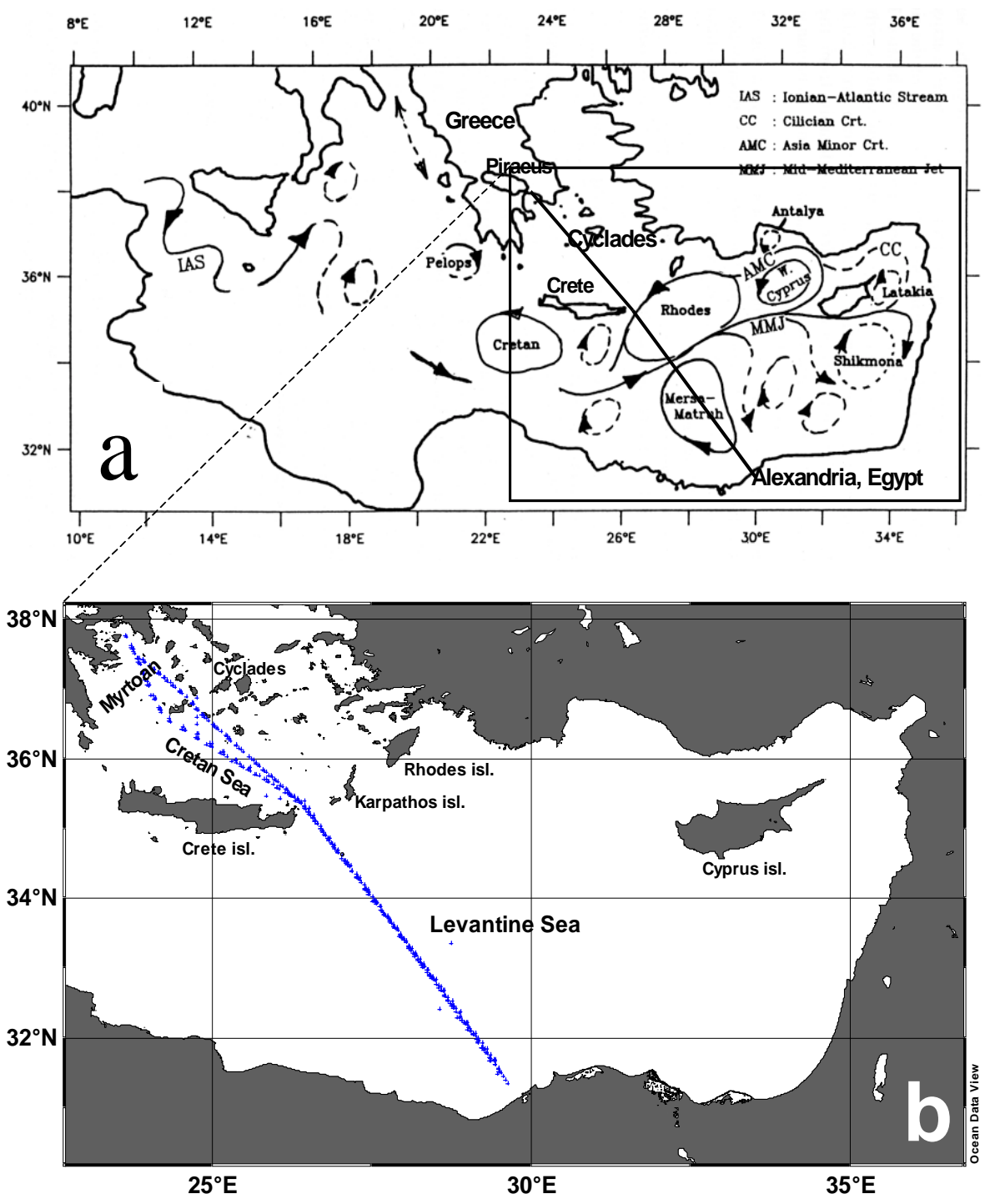

Fig. 1. (a) Schematic representation of the sub-basin scale circulation of the eastern Mediterranean, as estimated by Robinson et al. (1991) (from Zervakis et al., 2001). Solid (dashed) curves represent permanent (transient) features. Superimposed on the figure by Robinson et al. is the Piraeus - Alexandria transect. Also, the island of Crete and the Cyclades archipelago are identified. The small transient anticyclonic feature between Rhodes and Cretan cyclones is the Ierapetra eddy. (b) The two different ship-tracks are shown as series of expendable bathythermograph (XBT) launching positions. The Myrtoan, Cretan and Levantine Seas are identified on the map. track, under the name Mid-Mediterranean Jet (MMJ). The MMJ's track appears to be determined by the presence of a series of permanent sub-basin scale features: the Cretan cyclone to the SW of the island of Crete, the Rhodes cyclonic gyre SE of Rhodes Island, and the large Mersah-Matruh anticyclone occupying a major part of the southern Levantine basin. Some semipermanent and recurrent eddies revealed by the POEM project were identified: the most important of them are the Ierapetra anticyclone appearing south of Crete (between the Cretan and Rhodes cyclones) and the Shikmona gyre south of the island of Cyprus at the easternmost part of the eastern Mediterranean.

Based on POEM results, the Piraeus - Alexandria shiptrack was expected to intersect the southwestern limits of the Rhodes gyre, and dissect the Mersah-Matruh gyre through its center. Through the XBT measurements along this track, the horizontal and vertical structure and the temporal evolution of these features, as well any deviations from the above described circulation features, were explored.
In the next section, the methodology used in XBT data collection and analysis is described. In addition, the satellite information necessary in describing the sub-basin scale features encountered is presented. Section 3 deals with the evolution of the thermocline and the circulation throughout the duration of the experiment and the differences observed among the 3 distinct basins encountered by the ship-track: the Myrtoan, the Cretan and the Levantine (Fig. 1b). The estimated geostrophic currents and transports are presented in Sect. 4. Finally, discussion of the results and conclusions are presented in the last section of this work.

\section{Methodology and logistics}

\subsection{XBT data collection and analysis}

The main difficulty faced in performing the XBT measurements along the Piraeus to Alexandria transect was related to 
Table 1. XBT PIRAEUS - Alexandria crossings

\begin{tabular}{lcc}
\hline Crossing & Date & XBT probes launched \\
\hline PIRALEX-1 & 23-24 October 1999 & 39 \\
PIRALEX-2 & 21-22 November 1999 & 35 \\
PIRALEX-3 & 4-5 December 1999 & 38 \\
PIRALEX-4 & 19-20 December 1999 & 34 \\
PIRALEX-5 & 21-22 January 2000 & 22 \\
PIRALEX-6 & 22-23 February 2000 & 36 \\
PIRALEX-7 & 17-18 March 2000 & 35 \\
PIRALEX-8 & 2-3 April 2000 & 35 \\
PIRALEX-9 & 18-19 April 2000 & 39 \\
PIRALEX-10 & 19-20 May 2000 & 36 \\
PIRALEX-11 & 10-11 June 2000 & 45 \\
PIRALEX-12 & 24-25 June 2000 & 39 \\
PIRALEX-13 & 8-9 July 2000 & 36 \\
PIRALEX-14 & 22-23 July 2000 & 36 \\
PIRALEX-15 & 24-25 September 2000 & 36 \\
PIRALEX-16 & 24-25 October 2000 & 37 \\
\hline
\end{tabular}

logistics. There is no direct liner connection between Greece and Egypt, and the marine trade between the two countries is rather low in volume. As a result, the cargo ship lanes carrying out the trade between Piraeus and Alexandria do not have a regularly repeating schedule, but instead depend on cargo availability. As the journeys are not regularly repeated, it was not always possible to maintain a bimonthly repetition of the track: there were times when more than 20 days intervened between successive trips, and other times when the trips were cancelled. A change of host ships that took place in June 2000 is reflected in the ship tracks: before that time, the track crosses the Cyclades archipelago, while afterwards the ship followed a route south of the island group. The January 2000 transect was interrupted due to a change in ship route.

The host ships have a cruising speed of 17-20 knots; thus, the XBT model of choice was the Sippican T-4 which reaches a depth of $460 \mathrm{~m}$. As the MFSPP-VOS requirements for XBT sampling was a profile every $10-12$ nautical miles, a probe was launched every 40-45 min. Each transect consumed an average of 37 probes.

A total of 16 crossings from Piraeus to Alexandria were performed ranging from October 1999 until October 2000. A summary of the 16 journeys are presented in Table 1.

Upon data acquisition on board the ship, a preliminary quality control was performed. Once the profile was accepted as valid, the data were decimated and transmitted to the MFSPP headquarters in Italy and incorporated in the assimilation procedure of the MFSPP forecasting model.

\subsection{Satellite images}

In the following analysis some satellite images of Sea Surface Temperature, obtained through the Deutsches Zentrum für Luft- und Raumfahrt (DLR) ISIS (Intelligent Satellite

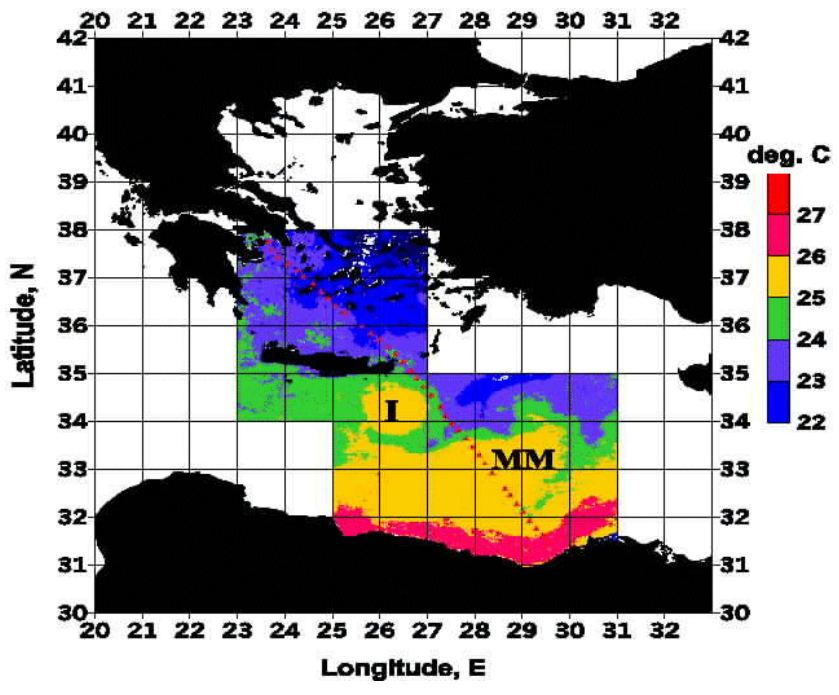

Fig. 2. Sea-surface temperature distribution during the first PIRALEX transect on 23 October 1999. The Ierapetra and MersahMatruh anticyclonic eddies are identified by their initials (I and MM, respectively). The positions of the XBT drops are marked by red triangles.

data Information System) web site (isis.dlr.de) were included. After downloading the images, the gray scale representation of the temperature field was converted to temperature values following DLR directions, and the images were projected upon a latitude/longitude grid, in order to obtain the geographical information and overlay the successive ship positions during XBT launches. Whenever an image from the day or week of the Piraeus - Alexandria crossing was not available (a problem usually due to cloudiness, appearing mostly in the winter), composite images from the corresponding month were used. These images were used to provide some information on the sub-basin scale features along the across-track dimension.

\section{Sub-basin scale features and thermocline evolution}

Before examining the evolution of the thermocline along the Piraeus - Alexandria transect throughout the MFSPP experiment, a satellite SST image obtained on 23 October 1999 (Fig. 2), during the first crossing of the transect, was used to identify sub-basin scale features responsible for the isothermal displacements recorded by the XBT transects (Fig. 3).

Comparison with the POEM-derived circulation (Fig. 1a) reveals a very similar circulation structure, however, with significant deviations. The circulation in the Levantine offshore region off Egypt is dominated by the Mersah-Matruh anticyclonic gyre, while closer to the coast (and parallel to it) there is a band warmer than $26^{\circ} \mathrm{C}$. As shown below, analysis of the XBT observations within this coastal feature has revealed the presence of an eastward-flowing coastal current, an extension of the North African current along the Egyptian coast. North of $34^{\circ} \mathrm{N}$, the characteristic circular sig- 

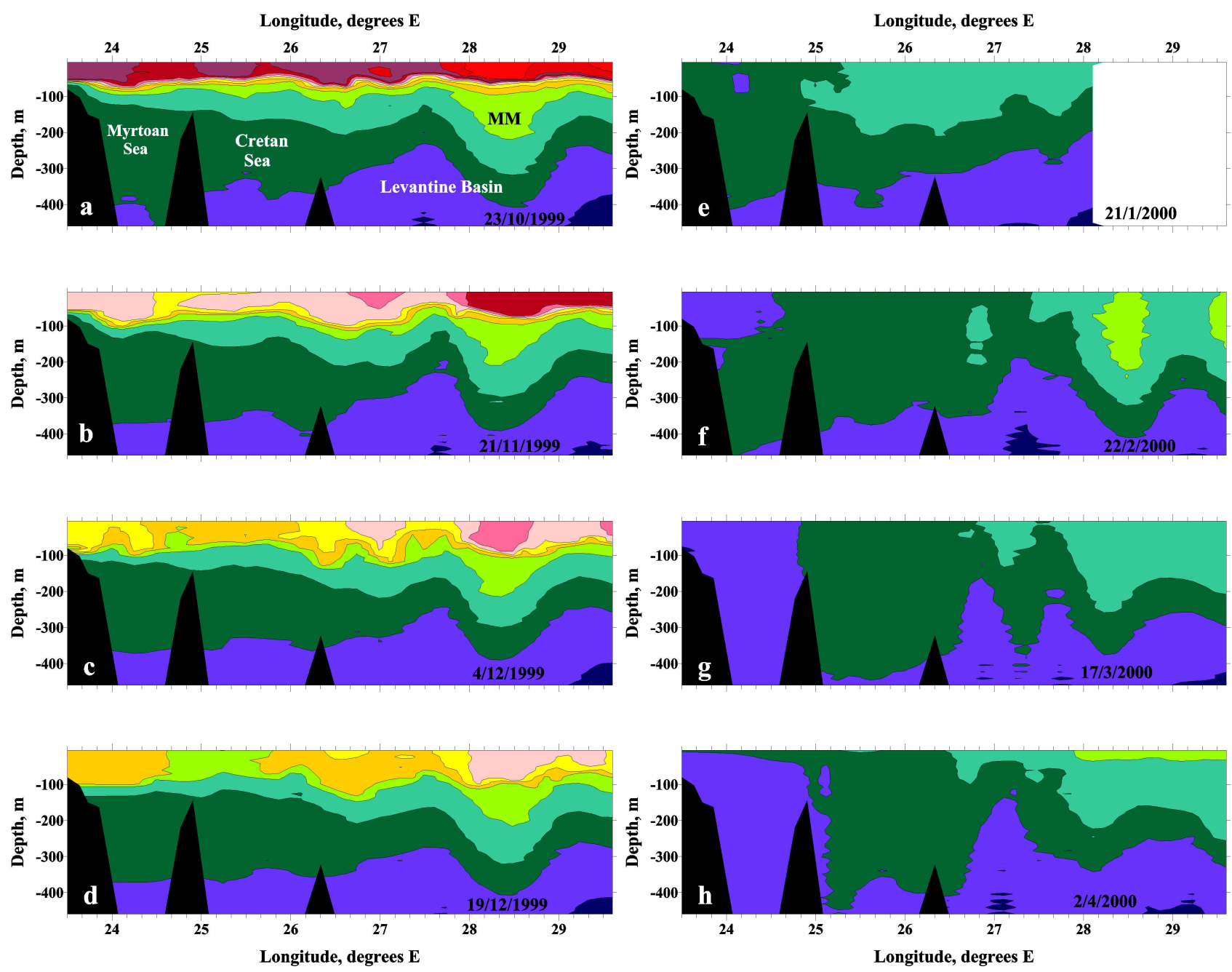

Fig. 3. Contours of temperature along the Piraeus to Alexandria transect.

nature of the Ierapetra anticyclone, identified as a recurrent feature by the POEM data (Robinson et al., 1991), was observed. The ship-track barely crosses the outer limits of the cyclonic Rhodes gyre; however, it crosses the outer extent of the Ierapetra anticyclone and intersects the Mersah-Matruh gyre through its center. Further north, in the Cretan Sea, the satellite image suggests the presence of a dipole (cycloneanticyclone) north of Crete, dominating the circulation there, in agreement with many recent works (Zervakis et al., 1998; Theocharis et al., 1999; Georgopoulos et al., 2000). The ship-track is not ideal for the resolution of the dipole structure, and, thus, the sub-basin scale circulation within the Cretan and Myrtoan Seas will not be examined.

Having identified the main circulation features crossed by the Piraeus to Alexandria transect, the thermocline evolution along the ship-track is described below. All the XBT transects from Piraeus to Alexandria are presented (Fig. 3). Based on the thermal structure of the upper $460 \mathrm{~m}$ of the ocean along the track during the first crossing, on 23-24 October 1999, the distinct marine regions of the Myrtoan and
Cretan Seas and the Levantine basin are identified (Fig. 3a). A significant depression of the $15-17^{\circ} \mathrm{C}$ isotherms within the longitude range of $28^{\circ}$ to $29^{\circ} \mathrm{E}$ reveals the presence of the Mersah-Matruh anticyclone, identified by "MM" in Fig. 3a. A rise of the isotherms between the Cretan Straits (at longitude $26^{\circ} 10^{\prime} \mathrm{E}$ ) and $27^{\circ} 30^{\prime} \mathrm{E}$ indicates the presence of a southwestward-flowing current (a possible extension of the Asia Minor current) just along the southeastern coast of Crete. The presence of a core of warm water in the surface layer at about longitude $27^{\circ} \mathrm{E}$ corresponds to the tangential crossing of the Ierapetra anticyclone. This fact is not so obvious in the temperature record; however, it becomes quite clear at a later section, when the geostrophic currents and transports across the Piraeus-Alexandria track are estimated. Further to the south (and east of $29^{\circ} 10^{\prime} \mathrm{E}$ ), the downwarping of the isotherms suggests an eastward coastal current. This current is also traceable in the sea-surface image (Fig. 2); the CTD-station network sampled during the POEM project did not extend far enough south to reveal its presence, and, thus, this feature is absent in the POEM-derived circulation 

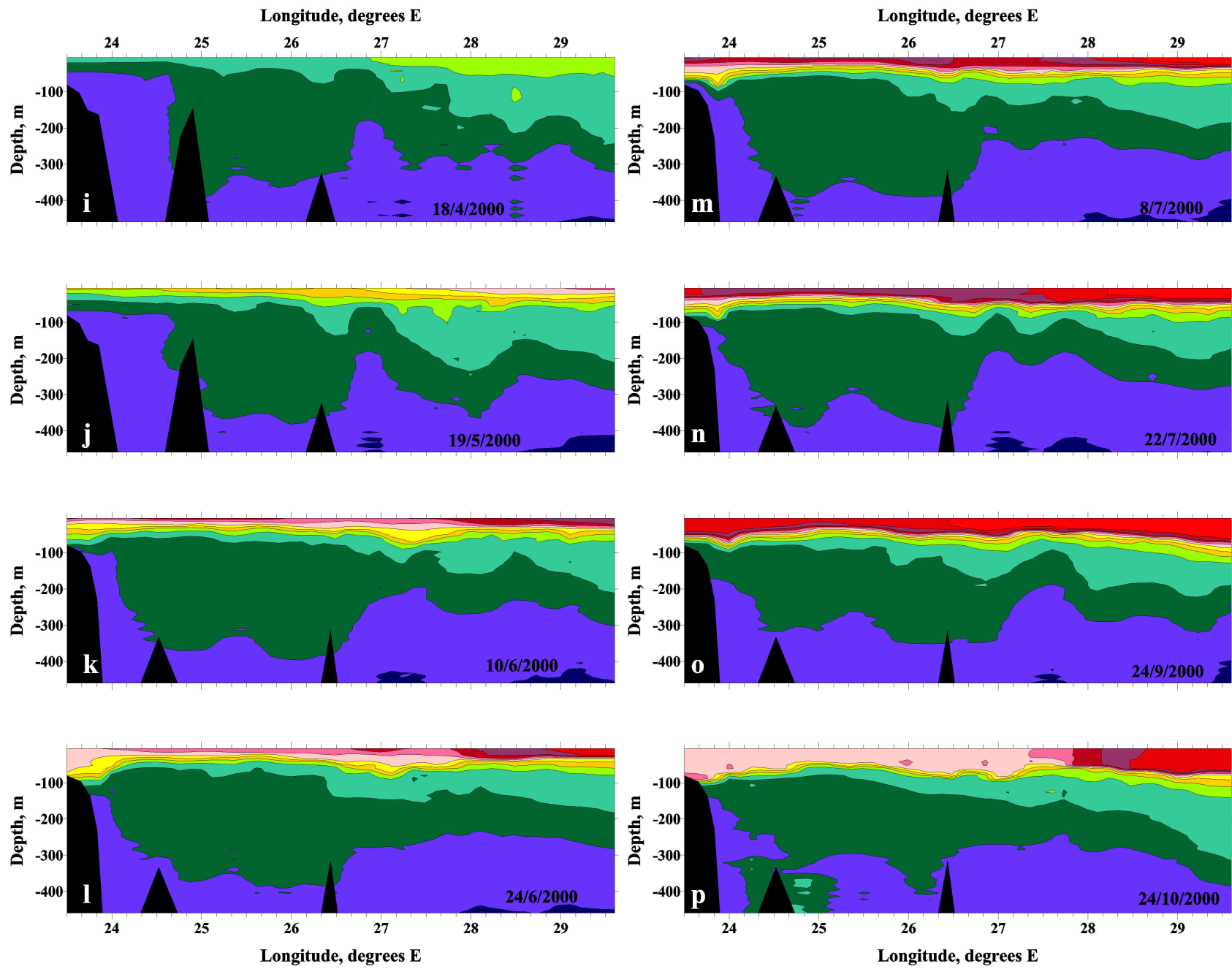

Fig. 3. continued

(Fig. 1). However, the presence of such an eastward coastal current along the eastern part of the North African coast can be expected from theory and is traceable in a multitude of SST images from the region (e.g. Figs. 2 and 4).

In terms of the vertical structure of the thermocline and its evolution, a very steep thermocline at a depth of about $50 \mathrm{~m}$ extends all the way from the Myrtoan Sea to the Levantine. The temperature of the surface layer varies from $23^{\circ} \mathrm{C}$ in the Myrtoan to more than $25^{\circ} \mathrm{C}$ in the Levantine. Examination of the sea surface temperature image (Fig. 2) reveals even higher variability, with the temperature in the Levantine reaching $27^{\circ} \mathrm{C}$ in October; however, this difference can be attributed to the skin temperature recorded by the satellite, and the rejection of the upper $5 \mathrm{~m}$ of the XBT profile due to the thermal inertia of the probes. The interface between the surface layer and the thermocline is very steep: a 4 to $6^{\circ} \mathrm{C}$ temperature decrease is recorded between 50 and $60 \mathrm{~m}$ depth. Below $100 \mathrm{~m}$ lies the seasonal thermocline, which increases in sharpness from north to south. Note that the vertical distance between the $15^{\circ} \mathrm{C}$ and $16^{\circ} \mathrm{C}$ isotherms is about $250 \mathrm{~m}$ in the Myrtoan Sea, $200 \mathrm{~m}$ in the Cretan Sea, and less than $100 \mathrm{~m}$ in the Levantine, and remains that way throughout all of 1999 (Figs. 3a-d). The warm surface layer progressively loses heat and increases in thickness to $100 \mathrm{~m}$ by late December. Of interest is the great stability that the Mersah-Matruh anticyclone exhibits throughout the fall of 1999, both in size and position.

In January 2000, the southern Levantine was not sampled due to an unexpected change of route of the host ship. However, the data acquired in the Myrtoan Sea reveal a deep thermal homogenization of the upper ocean, reaching down to $400 \mathrm{~m}$ (Fig. 3e). The convection processes did not reach that depth in the Cretan Sea in January, but only later, in February (Fig. 3f). A $100 \mathrm{~m}$-thick thermal inversion emerges in the surface Myrtoan Sea in February. This is a clear indication of the role that the Black Sea waters play in the western Aegean: their mixing with the underlying waters of Levantine/Cretan origin dilutes the latter to lower salinities. In February (Fig. 3f), the heat loss of the near-surface waters of the Myrtoan brings such a temperature homogenization that 

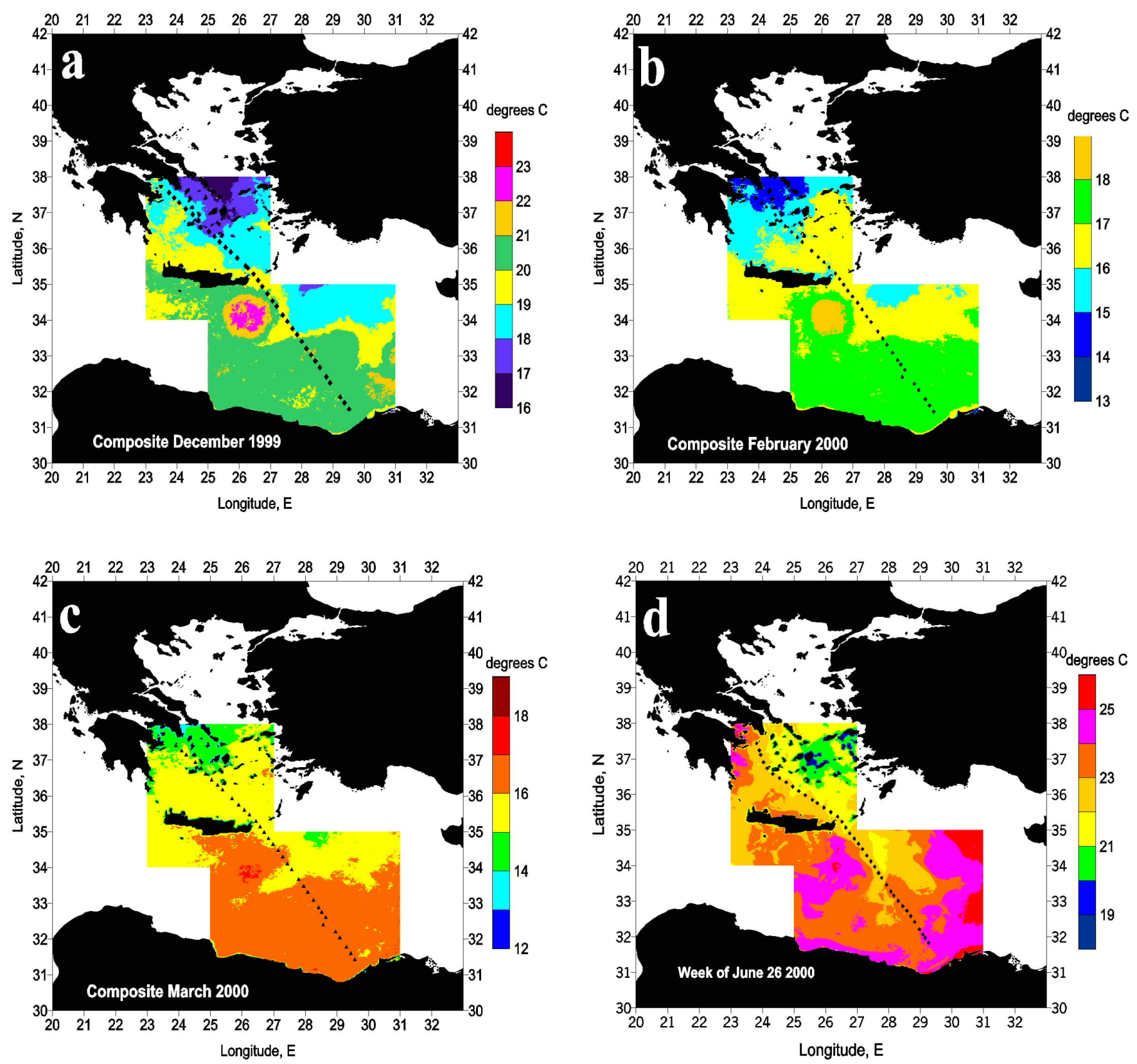

Fig. 4. Sea surface temperature distribution in (a) December 1999, (b) February, (c) May and (d) June 2000.

salinity becomes the stratifying variable. As the near-surface waters of the western Aegean have been subjected to dilution, thus, having a low-salinity signal, they can be identified by a $100 \mathrm{~m}$-thick temperature inversion.

Maximum convection appears in the Aegean Sea in March (Fig. 3g): the depth of convection has exceeded $460 \mathrm{~m}$ in the Myrtoan Sea, and was somewhere between 400 to $460 \mathrm{~m}$ in the Cretan Sea; homogenization did not reach so deep in the Levantine, where the $16^{\circ} \mathrm{C}$ isotherm was ventilated just south of the Cretan Straits. During this coldest month, the temperature of the upper layer of the Myrtoan Sea is less than $15^{\circ} \mathrm{C}$, while in the Cretan Sea it is less than $16^{\circ} \mathrm{C}$. Furthermore, a change in the circulation in the Levantine is ob- served in March: the Mersah-Matruh anticyclone is not directly identifiable any more, and smaller horizontal scales are recorded. Examination of satellite images of sea-surface temperature reveals that indeed the Mersah-Matruh anticyclone, while present in December 1999, is not present in either February or March 2000 (Figs. 4a-c). As for the Ierapetra anticyclone, the surface signature starts to disintegrate in March 2000. In the deep layer, the slope of the isotherms off the Cretan Straits indicates an increase in the pressure gradient across the Straits, suggesting an increase in the speed of the southwestward current SE of Crete by the formation of a deep front (Fig. 3g).

The first signs of re-stratification were recorded in 
April 2000, characterized by very shallow surface layers (Figs. 3h and i). The deep isotherms SE of Crete retain their frontal character and the Mersah-Matruh anticyclone does not regain the strong signature it displayed before March 2000. This fact suggests that the Mersah-Matruh anticyclone has moved either away from the ship-track, or it did not build up to its previous strength through the duration of the experiment. The satellite images suggest that the Ierapetra anticyclone tends to be reformed during summer, but there is no trace of the Mersah-Matruh gyre evident (Fig. 4d).

The progressive rebuilding of the thermocline continues throughout all the track crossings until September (Figs. 3jo). Finally, the surface layer of October 2000 is 2 to $3^{\circ} \mathrm{C}$ cooler and significantly thicker than in 1999, a fact suggesting that the seasonal thermocline erosion process started earlier in the year 2000 than in the year 1999.

\section{Geostrophic currents and transports}

\subsection{Estimating geostrophic velocity profiles}

The estimation of geostrophic velocities across a hydrographic transect is a standard procedure, given the accurate description of the fluid based on the equation of state: records of temperature, salinity and pressure leads to the determination of density, specific volume and the dynamic height above a level of no motion. The use of XBT technology for operational monitoring, using VOS as instrument-launching platforms, exhibits quite a few advantages (related mostly to cost and logistics), but also a major disadvantage: temperature and depth (translated to pressure) alone cannot determine the state of the fluid. For that purpose, a third variable, salinity, is necessary. There are a few ways to overcome this problem, but all are based on the same principle: the determination of the $\theta / S$ curve within the depth range and area of interest, the exploitation of this curve in describing salinity as a function of potential temperature $(S=S(\theta))$, and the use of such a relationship in computing a virtual salinity profile for each temperature profile from the XBTs. The different approaches for the determination of salinity to be used in the $\theta / S$ diagram are:

1. The most accurate method would be to launch expendable CTD probes (XCTDs) at regular intervals along the XBT sampling, thus, determining the $\theta / S$ relation within the depth range of interest. This method is preferable, especially for the upper ocean, as it provides detailed information on the salinity signatures of any sub-basin scale features; however, it is quite expensive, as the cost of XCTDs is more than one order of magnitude greater than that of XBTs.

2. When the use of XCTDs is logistically impossible, $\theta / S$ relationships from recent CTD surveys can be used.

3. Another approach would be to use $\theta / S$ relationships from climatological databases. This method is most efficient in well-documented regions of the world ocean, where databases can provide both a good resolution of the seasonal cycle, as well as statistics on the interannual and seasonal distribution of the hydrographic variables.

The use of XCTDs was not an option, thus, the possibility to adopt either approach 2 or approach 3 to determine the $\theta / S$ relationship was examined. It was not possible to use approach 2, because there weren't any recent oceanographic cruises in that region. The most recent cruise was the Greek R/V AEGAEO's trans-Mediterranean Cruise in the framework of the EU project MTP-II MATER in June 1999. Furthermore, as upper ocean data are subject to air-sea interaction and intense circulation features, the $\theta / S$ relation is subject to changes in monthly temporal scale. A single hydrographic cruise might determine the $\theta / S$ relationship for a certain month of year 1999, but this relationship would be inappropriate for use in the remainder of the year.

Approach 3 would have been a reasonable solution, assuming there was enough information available for complete temporal coverage of the seasonal cycle of the hydrographic properties on a monthly resolution. This was not the case: the MEDATLAS (Fichaut et al., 1999) database contained information from the Levantine region only for the months of March, April, August and October; such fragmented information of the seasonal variability was not considered adequate for the determination of the continuous evolution of the $\theta / S$ parameters. Use of inappropriate $\theta / S$ relations would lead to very large salinity errors due to extrapolation of the $\theta / S$ curves. Thus, an alternative approach was adopted.

A version of the Princeton Ocean Model (Blumberg and Mellor, 1987) had been developed by the Laboratory of Physical Oceanography of the University of Athens to provide daily operational forecasts of circulation and hydrographic variability of the eastern Mediterranean in the framework of the "POSEIDON" project (Korres et al., 2002; Soukissian et al., 1999). The data obtained from the monitoring component of the "POSEIDON" project, as well as the information provided by the MFSPP-VOS project and described in the current paper, have offered unique opportunities for assessing the skill of the POM model in predicting upper-ocean conditions (Nittis et al., 2001; Zervakis et al., 2002). The skill assessment has shown that the model successfully describes the seasonal evolution of the thermocline and (as far as the available data show) the hydrographic characteristics of the upper ocean. Thus, the stored operational model output was used in order to obtain a $\theta / S$ relation for each time during the 1999-2000 period when there are XBT data available from the Piraeus-Alexandria VOS transect. The modelpredicted $\theta / S$ values were compared to climatological $\theta / S$ values, when available, providing a good assessment of the model simulation of hydrographic parameters, and, thus, the estimation of salinity as a function of temperature.

This method was applied only to the region of the Levantine, and was not extended to the Aegean Sea. The main reason for this was, as presented in the next paragraph, the upper $200-300 \mathrm{~m}$ of the Aegean Sea is almost fully homogenized 


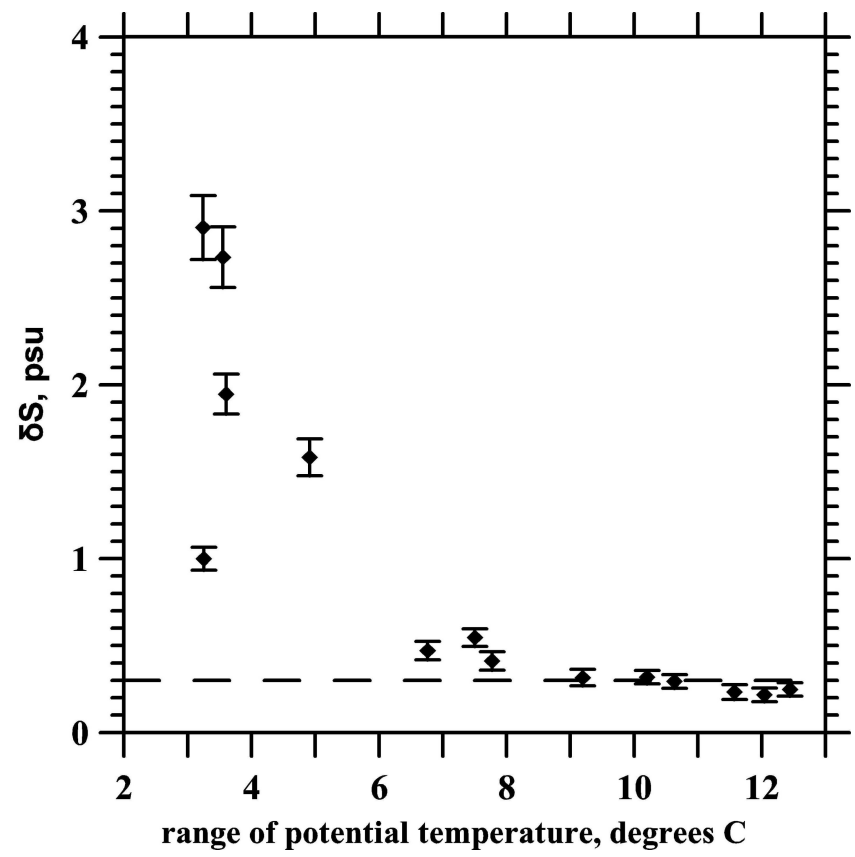

Fig. 5. The dependence of the width of the salinity confidence intervals $\delta S$ on the range of potential temperature values used in each polynomial fit is presented. The dashed line represents the level $\delta S=0.3 \mathrm{psu}$, where the confidence intervals appear to become independent of the range of potential temperature.

vertically during spring, and, as a result, salinity may become more important than temperature in the determination of density and, thus, geostrophic velocities. Furthermore, the intrusion of near-surface low-salinity waters of Atlantic or BlackSea origin in the upper layers of the Aegean (Theocharis et al., 1999) makes the water column statically stable, even if temperature inversion occurs. Both phenomena are unfavorable for the application of a method of salinity estimation from temperature profiles, due to the large errors introduced in the first case, and the inability to define a function in the second case.

For the determination of the $S=S(\theta)$ functions polynomial fits based on the singular value decomposition method (Press et al., 1992) were applied. The best results were obtained for 2 nd degree polynomials. The first attempts to obtain intervals of possible variability (hereafter referred to as confidence intervals) around the produced mean $S=S(\theta)$ profiles were based on the standard deviation of the fitted polynomial coefficients.

\subsubsection{Estimating confidence intervals}

The method described above produced quite acceptable $S=$ $S(\theta)$ functions for the production of salinity profiles, which (as shown in the following sections) were used in estimating dynamic heights for each station, and obtaining across-track profiles of geostrophic velocity relative to $460 \mathrm{~m}$ depth.

To assess the performance of the method, the "mean con- fidence interval index" $\delta S$ was devised, defined by

$\delta S \equiv \frac{1}{2} \sum_{\text {all }}\left(S_{\max }-S_{\min }\right)$,

where $S_{\max }, S_{\min }$ are the maximum and minimum salinities estimated through variation of the fitted coefficients by one standard deviation, obtained through the application of the singular value decomposition method. The results were not very encouraging: while the mean confidence intervals of salinity were quite narrow (of the order of $0.3 \mathrm{psu}$ ) in the stratified seasons, they increased greatly during periods of homogenization, reaching values of almost 3 psu (Fig. 5). This was due to the dependence of the multinomial fit to the range of the independent variable. In October, the temperature over the top $460 \mathrm{~m}$ of the water column varies from $13.8^{\circ} \mathrm{C}$ to more than $25^{\circ} \mathrm{C}$ (Fig. 6a), while in April it only reaches $18^{\circ} \mathrm{C}-\mathrm{a}$ full range barely exceeding $4^{\circ} \mathrm{C}$ (Fig. 6d). As a result, there is not enough range so as to define the polynomial fit with good confidence.

To overcome the problem of errors that are too large in the winter months, an alternative method is introduced, by assuming that the level of allowed salinity variance around the estimated fit should not exceed the $\delta S=0.3 \mathrm{psu}$, a value appearing not to depend upon the temperature range (Fig. 5). The allowed salinity variability is demonstrated for the months of October and April (Figs. 6b and e). Assuming that the adopted salinity variability was acceptable, it was converted to an interval of salt-induced variability of geostrophic speed estimates. For that purpose, the following methodology was devised. For each XBT profile, based on the corresponding month's $\theta / S$ relation, an expected dynamic height, plus profiles of minimum and maximum dynamic heights, were estimated based on maximum and minimum expected salinities. The estimation of mean expected velocity $U$ was computed naturally from the difference between the two expected heights at the corresponding pair of stations $i$ and $j$. The estimation of the minimum (maximum) expected geostrophic velocity was computed from the difference between the minimum (maximum) height of station $i$ and the maximum (minimum) height of station $j$. The expected range of variation of velocity, $\delta U$, around the estimate of the expected value $U$, was defined as the difference between the estimates of maximum and minimum velocity divided by two:

$\delta U \equiv \frac{1}{2}\left|U_{\max }-U_{\min }\right|$.

Having established a measure of the confidence interval around the expected velocity estimate, the estimates of allowed salinity variation $\delta S= \pm 0.3$ psu were applied to the estimation of velocity. The result was disappointing. The obtained $U_{\max }$ and $U_{\min }$ were one order of magnitude higher than the expected estimate $U$, and usually of different signs. The reason was recognized to be the unrealistic assumption of large salinity variation at deeper than $100 \mathrm{~m}$ depths. The "spread" of the climatological $\theta / S$ value (Figs. 6b and e) 

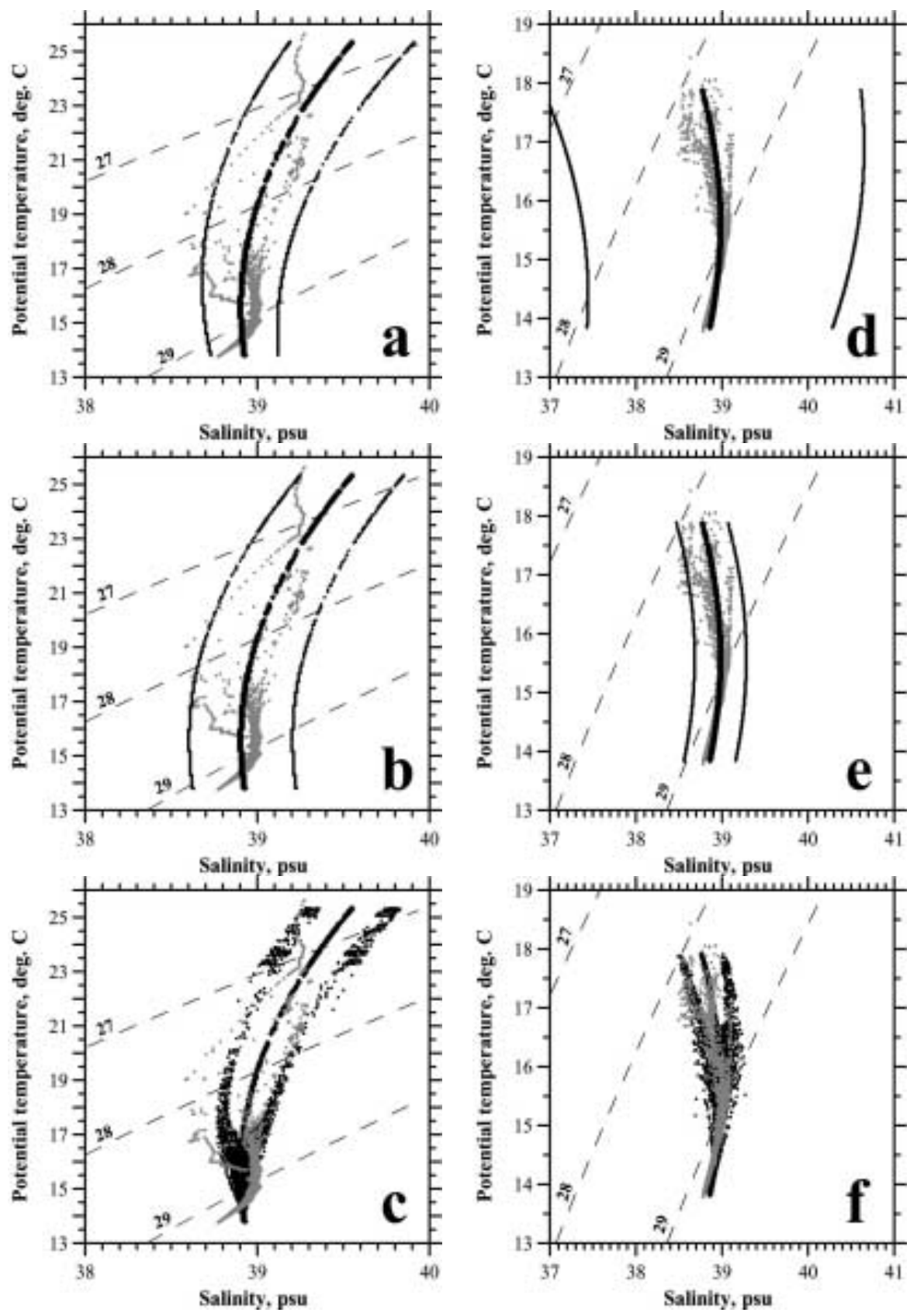

Fig. 6. The mean polynomial fit (thick black points), along with the minimum and maximum estimates (thin black points) as computed for the October 1999 (a) and April 2000 (d) POSEIDON model runs. Overlaid in gray points are the available MEDATLAS data from the region. The mean fits with a $\delta S= \pm 0.3$ psu are presented in (b) and (e) for October and April, respectively. The fits with $\delta S=$ $\pm 0.3 \exp (-z / 100 \mathrm{~m})$ are shown in $(\mathbf{c})$ and (f) for October and April, respectively.

over the Levantine is around 0.6 psu near the surface, collapsing to less than 0.05 psu below $100 \mathrm{~m}$. Thus, in reality, the deeper waters are essentially horizontally homogeneous in terms of salinity. For salinity anomaly estimation, by allowing a depth-independent salinity anomaly of $+0.3 \mathrm{psu}$ at station $i$ and -0.3 psu at station $j$, a $460 \mathrm{~m}$ deep salinity front of $0.6 \mathrm{psu}$ change over a distance of about $20 \mathrm{~km}$ was imposed. Such a front would be responsible for speeds exceeding $1 \mathrm{~m} / \mathrm{s}$.

To overcome this problem, an exponential profile of salinity anomaly, $\delta S=\delta S_{0} e^{-z / b}$, where $z$ represents depth in $\mathrm{m}$ and $b=100 \mathrm{~m}$, was introduced. $\delta S_{0}$ is defined as the salinity anomaly at the sea surface. The results in $\theta / S$ space are pre- sented for October and April (Figs. 6c and f, respectively). The allowed "spread" of the computed $\theta / S$ values from the XBT profiles simulates very well the corresponding climatological data. A sea-surface salinity anomaly $\delta S_{0}= \pm 0.3 \mathrm{psu}$, as suggested above, was used. However, this salinity variability was recorded over distances of the order of $500 \mathrm{~km}$ and more. To simulate salinity gradients between two successive XBT profiles, a $\delta S_{0}= \pm 0.1$ psu was chosen for estimating the expected geostrophic velocity. This value is more appropriate for the region, as the Levantine basin is rather far from sources of low or high salinity, and, thus, very high salinity gradients are not expected. The river Nile's outflow is downstream from the area of interest, and the Modified At- 

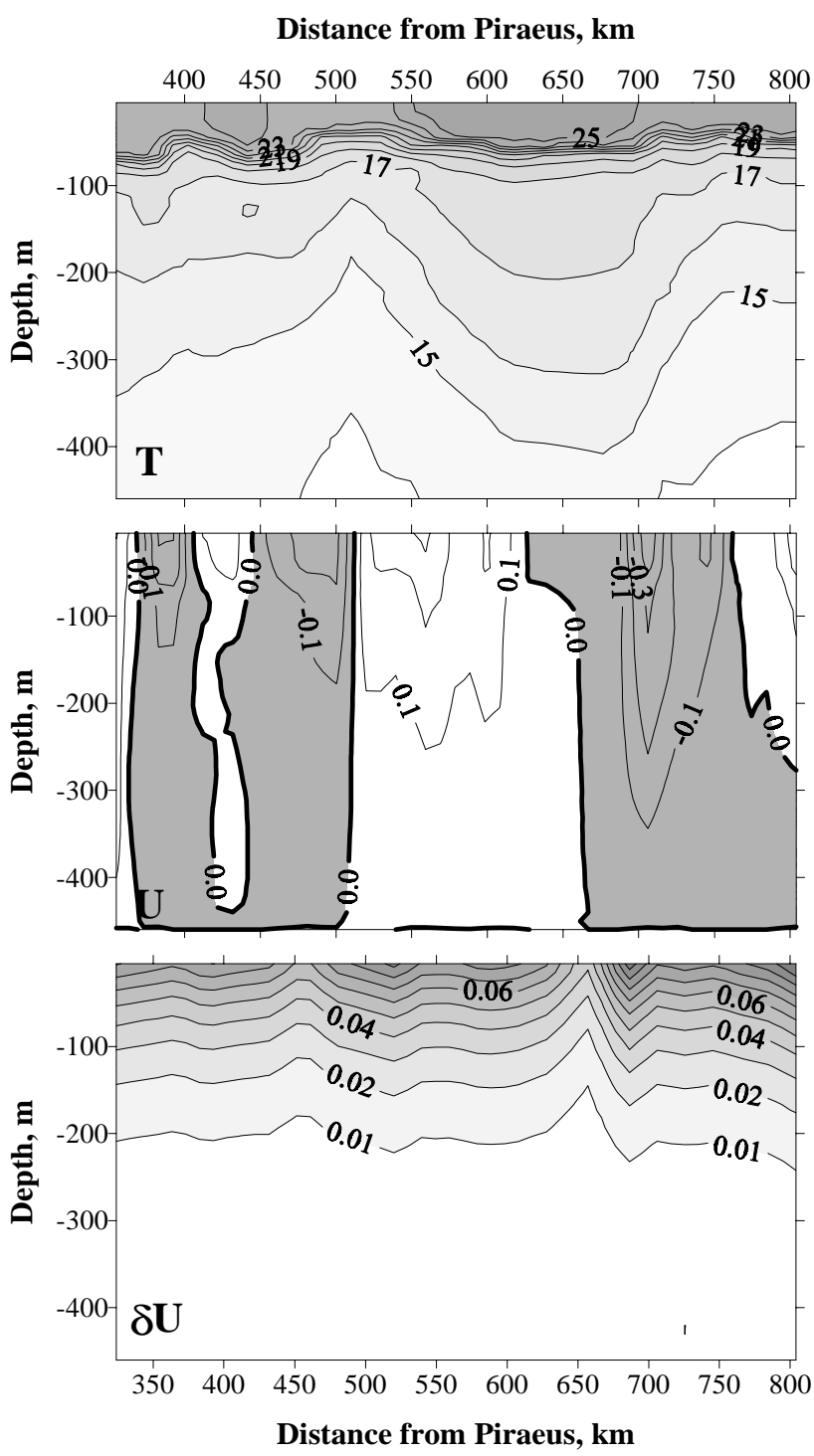

Fig. 7a. Contours of temperature (top), cross-track geostrophic velocity $U(\mathrm{~m} / \mathrm{s})$ relative to $460 \mathrm{~m}$ (center) and possible salt-induced velocity error $\delta U$ (bottom), along the transect from Cretan Straits to Alexandria selected crossings. In the central panel, the shaded (clear) regions denote velocity towards the southwest (northeast).

lantic Water spreading eastwards has been subjected to dispersion over its long route; thus, it should not create very strong fronts with local highly saline surface waters.

The above assumptions lead to velocity confidence intervals of the order of $7-10 \mathrm{~cm} / \mathrm{s}$ near the surface, less than $5 \mathrm{~cm} / \mathrm{s}$ below $50 \mathrm{~m}$, and less than $1 \mathrm{~cm} / \mathrm{s}$ below $200 \mathrm{~m}$ depth, which are thought reasonable, always keeping in mind that these are across-track velocities relative to $460 \mathrm{~m}$ depth.

\subsection{Geostrophic current structure}

Application of the method described above provided vertical profiles of the across-track geostrophic velocities along the ship-track from the Cretan Straits to Alexandria. The
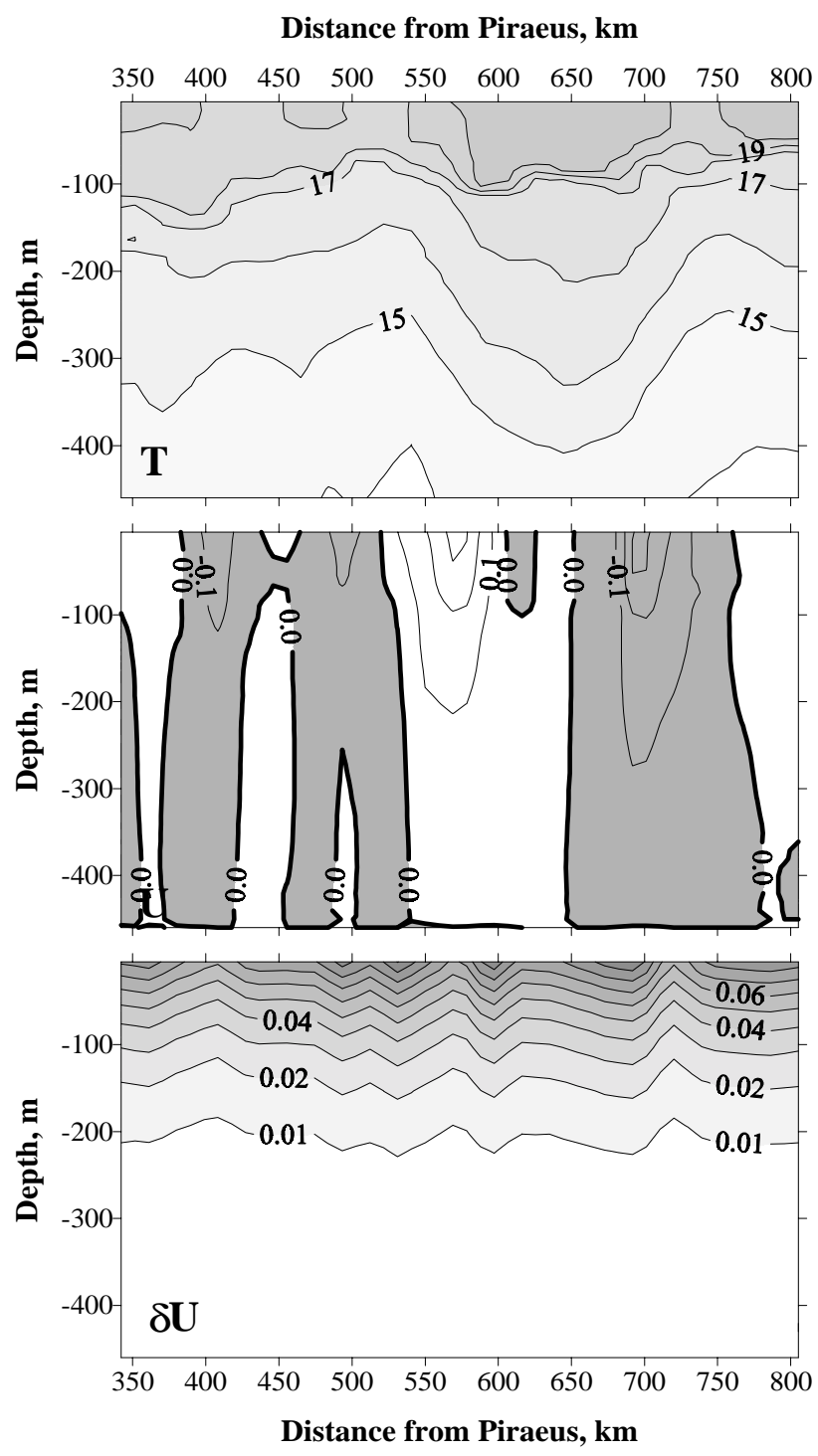

Fig. 7b. As in Fig. 7a, for the 4th crossing on 19 December 1999.

observed temperature field, along with the corresponding geostrophic across-track velocities and the potential error induced by the salinity estimation, are presented for selected crossings (Fig. 7).

The velocity field during the first crossing, on 23-24 October 1999 (Fig. 7a), indicates that the southwestward nearsurface current, located between 350 and $400 \mathrm{~km}$ from Piraeus, is either an extension of the Asia Minor current, or surface waters exiting from the Cretan Sea through the Straits and turning to the southwest. There is no associated surface signature in the sea-surface temperature satellite images (Figs. 2 and 4) that could shed more light on the origin of this current. The current reaches a maximum of $30 \mathrm{~cm} / \mathrm{s}$ at the surface; its vertical extent suggests that it is restricted to the surface mixed layer.

Further to the southwest, between 400 and $500 \mathrm{~km}$ from Piraeus, the ship-track encounters a sign reversal of the 

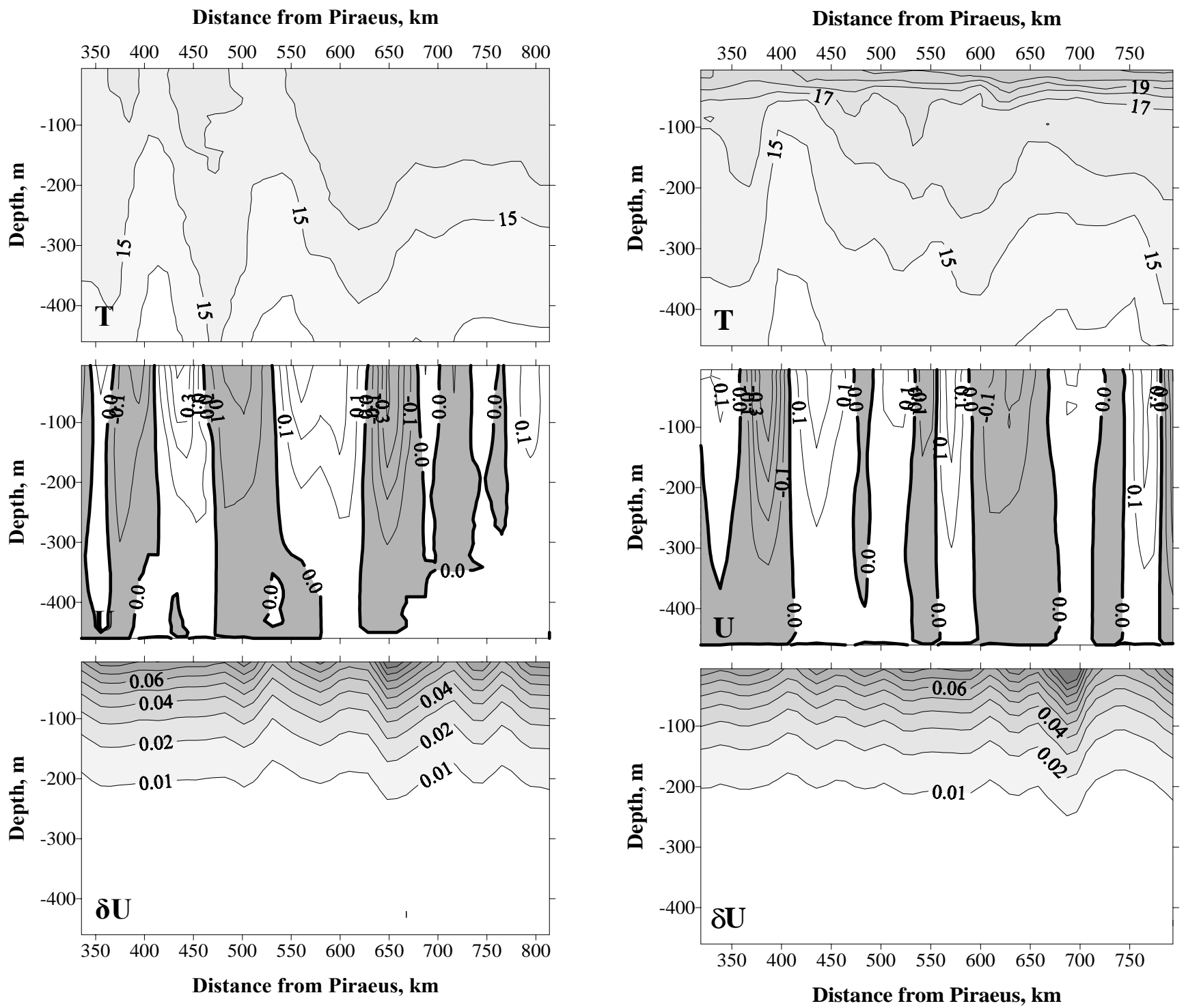

Fig. 7c. As in Fig. 7a, for the 7th crossing on 17 March 2000.

geostrophic velocity, initially towards the northeast and then towards the southwest. The signal is not very strong, but is repeated throughout all crossings until March 2000. Comparison with the satellite images (Figs. 2 and 4) certifies that it is the weak signature of the deep Ierapetra gyre. The ship follows an almost tangential track to the Ierapetra anticyclone, crossing its northeast boundary, and for that reason the estimated across-track velocities are small (the southwestward component exceeds $20 \mathrm{~cm} / \mathrm{s}$ near the surface) but consistent.

Further to the southwest along the ship-track lies the large signature of the Mersah-Matruh gyre, identified as a downwarping of the isotherms by more than $150 \mathrm{~m}$, and by the opposite sign velocities corresponding to the different isotherm slopes on the two sides of the core of the eddy. The anticyclone appears very strong (with speeds exceeding $40 \mathrm{~cm} / \mathrm{s}$ near the surface) and deep (with speeds of the order of $10 \mathrm{~cm} / \mathrm{s}$ recorded at depths exceeding $300 \mathrm{~m}$ ). The depth

Fig. 7d. As in Fig. 7a, for the 10th crossing on 19 May 2000.

of the $14^{\circ} \mathrm{C}$ isotherm suggests that the overall depth of the Mersah-Matruh anticyclone is deeper than $460 \mathrm{~m}$. Thus, the geostrophic currents relative to $460 \mathrm{~m}$ are probably underestimates of the absolute velocities, as there should be a significant contribution to the dynamic height estimates from the deeper-than- $460 \mathrm{~m}$ water column. The MersahMatruh anticyclone is a very stable feature of the region; it is present without any significant changes in all crossings until March 2000.

Further to the southwest of the Mersah-Matruh anticyclone, the isotherms have a downward slope, and geostrophy suggests a northeastward flowing coastal current exceeding $20 \mathrm{~cm} / \mathrm{s}$. It is probably an extension of the North African current flowing along the Egyptian coast. This coastal current had not been recorded by the POEM project, due to the limited southward extension of its sampling network; however, it is present both in modelling studies and satellite SST 

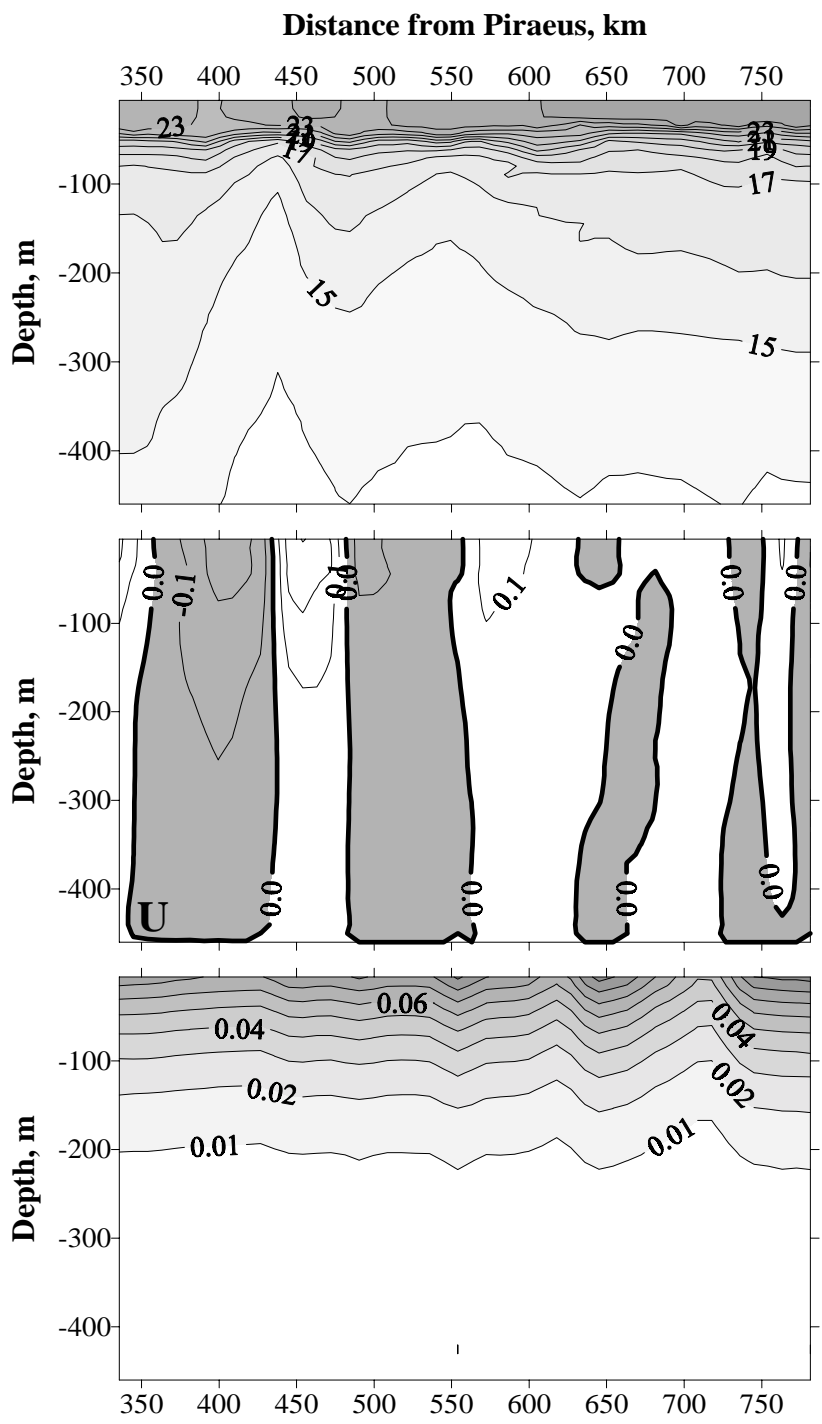

Distance from Piraeus, $\mathrm{km}$

Fig. 7e. As in Fig. 7a, for the 14th crossing on 22 July 2000.

images of the region.

The sub-basin scale features identified above are present throughout 1999, without significant changes (Fig. 7b). As mentioned above, the sub-basin scale circulation undergoes major changes (Fig. 7c) in March 2000. The southwestward current on the southwest of Crete intensifies as the $15^{\circ} \mathrm{C}$ isotherm upwarps $350 \mathrm{~m}$ within $25 \mathrm{~km}$; the associated geostrophic current now extends to $300 \mathrm{~m}$, as deep as the homogenized surface layer in the Cretan Sea.

The local signature of the Ierapetra anticyclone appears to be greatly intensified, suggesting a possible migration of the structure's center closer to the ship-track. The MersahMatruh anticyclone, while still associated with speeds exceeding $40 \mathrm{~cm} / \mathrm{s}$, does not retain its large horizontal scale; a smaller anticyclone centered at about $600 \mathrm{~km}$ from Piraeus could be associated with Mersah-Matruh: in that case, one possibility could be that the large eddy has moved towards

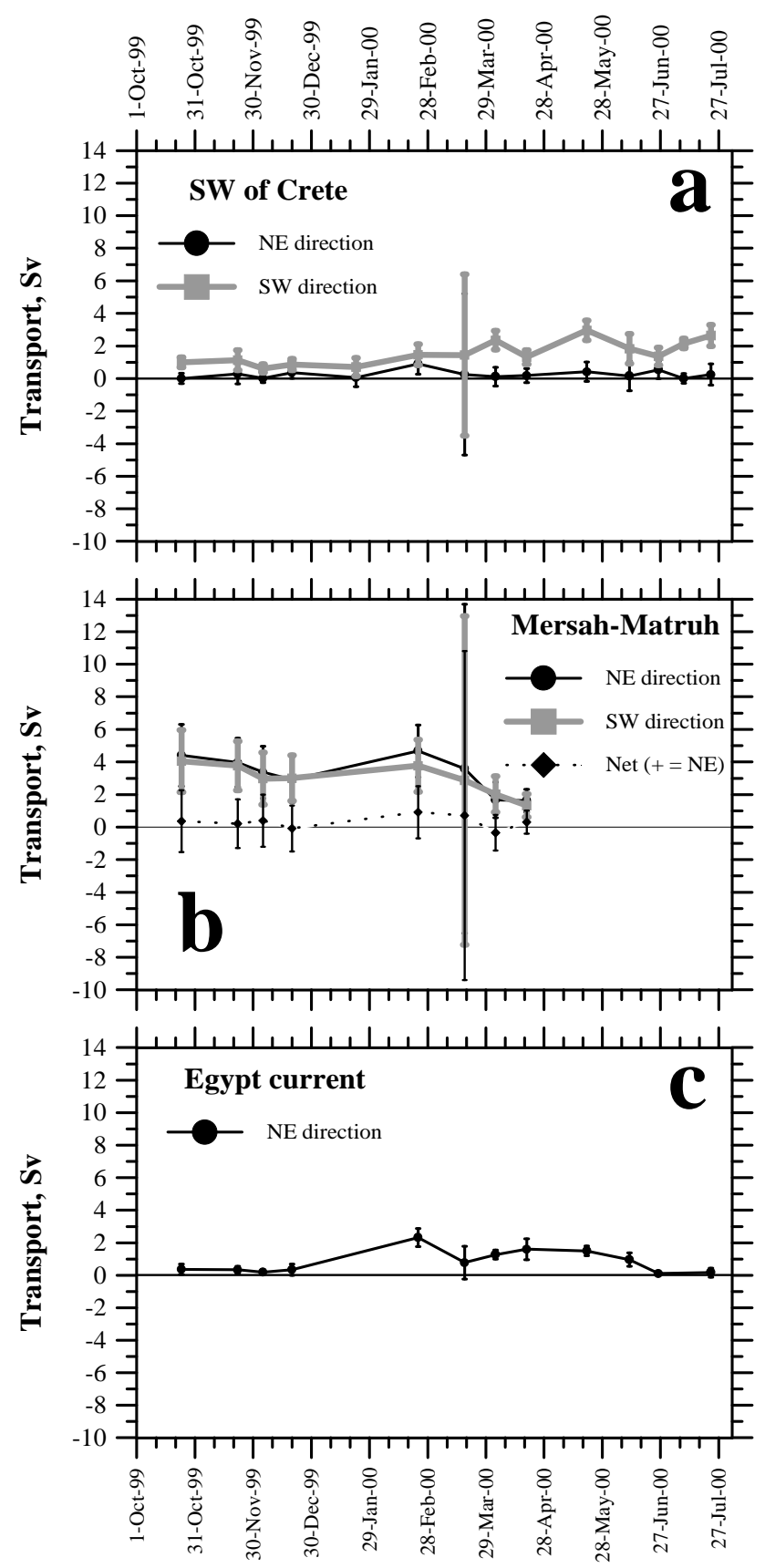

Fig. 8. Estimated transports for (a) the southwestward current SW of Crete, (b) the Mersah - Matruh gyre and (c) the coastal current off the Egyptian coast.

the northeast (Najwa Hamad, personal communication), and the ship-track does not cross the eddy through its center. Another possibility is that Mersah-Matruh is shrinking, following the general decrease of the horizontal scale of mesoscale structures due to a decrease in Rossby radius of deformation associated with springtime homogenization processes (Zervakis et al., 1998). Unfortunately, a good quality SST image from March 2000 was not obtained.

After March 2000 (Figs. 7d and e), the southwestward cur- 
rent near Crete retains its intensified deep flow until at least July 2000. The single other recognizable circulation feature is the northeastward coastal current off Egypt, which is present throughout the experiment. The horizontal scale of the other synoptic and mesoscale structures becomes quite small by late spring (Fig. 7d), but slowly grows again as stratification builds up in summer (Fig. 7e), and the associated speeds are much smaller than before March 2000.

\subsection{Geostrophic transports}

The horizontal transports associated with the distinct circulation features described above were estimated by integrating horizontally and vertically the across-track geostrophic velocity fields described in the above paragraphs (Fig. 8). The error increases dramatically in March, a time of minimum thermal stratification, where salinity differences are expected to play a significant role in determining differential densities critical to the horizontal pressure gradients and geostrophic velocities. In defining the horizontal and vertical limits of each eddy or jet, the zero-isotach, i.e. the line along which the cross-track velocity changes sign, was utilized. Thus, the extent of the Mersah-Matruh gyre (before its destruction) was always defined. For the southwestward Cretan current, the situation was not so clear, and the northeastward flow north of the current was included for the sake of comparison. The transport estimates for the Egyptian current are plagued by the fact that XBT sampling was interrupted before entering the Egyptian national waters, and that the last XBT was not always dropped at the same distance from Piraeus. Thus, the transport estimates for the Egyptian current are only good as an order-of-magnitude calculation of the minimum transport associated with the extension of the North African current. Finally, as the ships-track was near-tangential to the Ierapetra anticyclone, the corresponding transport estimates would have been meaningless.

The estimated transport of the Cretan current (Fig. 8a) amounts to only about $1 \mathrm{~Sv}$ before the March homogenization of the upper Cretan Sea; after that period, the current intensifies to $2-3 \mathrm{~Sv}$, and remains that high throughout the summer. It is possible that part of this intensification reflects Cretan Surface Water exiting the Kasos Strait and turning to the southwest. In that case, an upper limit of $2 \mathrm{~Sv}$ has to be considered for upper-water-column Cretan waters entering the Levantine Sea during spring-summer 2000.

Based on the evolution of the volume flux associated with Mersah-Matruh gyre (Fig. 8b), both the southwestward and northeastward components of the eddy amount to about $4 \mathrm{~Sv}$. The two opposite-sign components of the eddy match each other much better than what the error-bars would suggest, which is clearly demonstrated by the fact that the "net" transport across the whole eddy is not different than zero, when taking under consideration the salt-induced circulation errors. The above suggests (i) that the latter error estimates are probably overestimated, and (ii) the Mersah-Matruh anticyclone is probably a closed eddy, or a meander of the coastal current, whose return flow is fully covered by the ship-track.
Finally, based on our estimates for the coastal Egypt current (Fig. 8c), as mentioned above, its transport has probably been underestimated, as it has not been sampled all the way to the coast. Furthermore, a large part of the variability must be attributed to the varying extents of the current covered by XBT sampling. Having considered all the above, it is concluded that there is an extension of the North African current flowing towards the east along the northern coast of Egypt, and that this current transports a minimum of $1 \mathrm{~Sv}$ (a significantly smaller amount than the Mersah-Matruh eddy alone). The fact that the Egypt current appears to transport significantly less water than the Mersah-Matruh anticyclone suggests that the latter is probably a closed eddy and not a meander of the North African current.

\section{Conclusions and discussion}

A series of XBT observations along the Piraeus - Alexandria transect, resolving the seasonal cycle of thermocline erosion and reformation throughout a year, have been presented. Furthermore, the spatial and temporal sampling frequency allowed for resolution of the sub-basin scale field and its evolution. Attention was mostly focused on the differences of the thermocline evolution between the Aegean and Levantine basins, and on the evolution of the sub-basin scale field in the Levantine. Also, special attention was given to the estimation of salinity and cross-track geostrophic currents from the XBT temperature profiles, along with a corresponding error analysis.

Overall, the observations reveal that:

- During winter 2000, the Myrtoan and Cretan Seas exhibited convection and vertical homogenization, exceeding 460 and $400 \mathrm{~m}$, respectively, while in the Levantine basin the thickness of the surface mixed layer did not exceed $200 \mathrm{~m}$.

- The denser waters produced in the Cretan Sea during the winter form a front with the Levantine waters in the region of the Cretan Straits, and the corresponding pressure gradient causes an increase in the southwestward transport south of Crete by $1-2 \mathrm{~Sv}$.

- The Mersah-Matruh anticyclone appears stable in the time period before the winter formation period. During March 2000, the anticyclone's signature progressively disappears from the transect, a sign either that the feature has moved, or that it has disintegrated to smaller scales.

- The latter effect (the disintegration of large sub-basin scale features into smaller ones during spring) is evidenced in this data set and can be attributed to the seasonal decrease in the internal deformation radius in winter, due to the decay of the degree of stratification.

- Furthermore, the data clearly demonstrate the existence of a coastal eastward current along the coast of Egypt, a possible extension of the North African current. 
- The lack of salinity measurements dictated the salinity estimation based on $\theta / S$ diagrams. The historical information available in Mediterranean databases (MODB, MEDATLAS) for that region of the Levantine basin was not adequate to offer either a good resolution of the seasonal cycle on a monthly basis or a good vertical resolution.

- For that purpose, the "POSEIDON" system's operational model predictions for the days of the ship crossings were utilized; the corresponding $\theta / S$ diagrams were produced, and the salinity as a function of temperature was estimated.

- The estimation of the velocity error due to salt-induced pressure gradients was based on an exponential salinity anomaly profile and the estimation of maximum and minimum across-track geostrophic velocity for each pair of consecutive XBT profiles.

- Geostrophic estimates suggest that the transport relative to $460 \mathrm{~m}$ of the Mersah-Matruh anticyclone was about $4 \mathrm{~Sv}$. The corresponding transport of the Cretan current varied from 1 to $3 \mathrm{~Sv}$, while the lower limit of the Egypt current transport was about $1 \mathrm{~Sv}$.

Since there are not many studies in this region of the Levantine basin, this study has improved the understanding of the physical oceanography of the region. However, the Piraeus to Alexandria track could not provide information on all significant questions regarding the circulation and exchanges of the region. For example, the Piraeus - Alexandria transect does not allow for a direct measurement of the Aegean-Levantine interaction. In the early nineties, massive production of very dense water took place in the Aegean Sea; as a result, there was an increased outflow of the Cretan Deep Water through the Cretan Straits and sinking to the bottom of the Levantine and Ionian basins, in the process thereby raising the previous bottom waters of Adriatic origin (Roether et al., 1996). This phenomenon, previously unrecorded, is known to the oceanographic community as the eastern Mediterranean Transient (EMT) (Malanotte-Rizzoli et al., 1999; Lascaratos et al., 1999). The rising of bottom waters is of great interest, not just to physical oceanographers and climate researchers, but also to biologists and ecologists, as it brings large amounts of nutrients close to the euphotic zone. Thus, the monitoring of the exchange between the Aegean and Levantine Seas is of utmost importance for the study of both seas. Due to the design of the Piraeus Alexandria transect, the only evidence obtained related to the Aegean - Levantine exchange was an increase in the Cretan current after the upper-ocean homogenization in the Cretan Sea. However, the existence of regular ferry lines connecting the islands along the Cretan Arc allows for the design of new tracks that would enable better monitoring and direct estimates of the exchanges between the two seas of the eastern Mediterranean. This objective will be among the aims in the design of the new tracks proposed for the successor project of the MFSPP in the Mediterranean Sea.
Acknowledgements. This project was supported by the EU/MAST3 MFSPP project under contract MAS3-CT98- 0171. We are indebted to the anonymous reviewers who have significantly improved the manuscript. Gratitude is expressed to Mr. Skopelitis and the Board of Directors of the Mediterranean Shipping Company, the captains, officers and crews of Mediterranean Shipping Company (MSC) SARISKA and ANASTASIA, and the MSC agents in Piraeus and Alexandria for their full support and hospitality throughout the data collection process.

Topical Editor N. Pinardi thanks C. Mooers and another referee for their help in evaluating this paper.

\section{References}

Blumberg, A. F. and Mellor, G. L.: A description of a threedimensional coastal ocean circulation model, In: Threedimensional Coastal Ocean Circulation Models, (Ed) Heaps, N. S., Coastal Estuarine Sci., 4, 1-16, Washington D. C., 1987.

Fichaut, M., Maillard, C., Balopoulos, E., Garcia, M.-J., Jourdan, D., and Dooley, H.: MEDATLAS 1997: Climatological Atlas and Multipurpose Database of observed temperature and salinity profiles of the Mediterranean Sea. Intern. Conference: Oceanography of the eastern Mediterranean Black Seasimilarities and differences of two interconnected basins, organized by the Institute of Oceanography of the National Center for Marine Research, Athens, 23-26 February 1999, 396-397, 1999.

Georgopoulos, D., Chronis, G., Zervakis, V., Lykousis, V., Poulos, S., and Iona, A.: Hydrology and circulation in the Southern Cretan Sea during the CINCS experiment (May 1994-September 1995), Progress in Oceanography, 46, 89-112, 2000.

Hecht, A. and Gertman, I.: Physical features of the eastern Mediterranean resulting from the integration of POEM data with Russian Mediterranean Cruises, Deep Sea Res., I, 48, 1847-1876, 2001.

Korres, G., Lascaratos, A., and Hatziapostolou, E.: The implementation of an Ocean Forecast System for the Aegean Sea, The Global Atmosphere and Ocean System, special issue: POSEIDON: An integrated operational oceanographic system, 8, 2-3, 191-218, 2002.

Lascaratos, A., Roether, W., Nittis, K., and Klein, B.: Recent Changes in Deep Water Formation and Spreading in the eastern Mediterranean Sea: a review, Progress in Oceanography, 44, 5-36, 1999.

Malanotte-Rizzoli, P. and Robinson, A. R.: POEM: Physical Oceanography of the eastern Mediterranean, EOS Trans. AGU, The Oceanography Report, 69, 194-203, 1988.

Malanotte-Rizzoli, P., Manca, B. B., d'Alcala, M. R., Theocharis, A., Brenner, S., Budillon, G., and Öszoy, E.: The eastern Mediterranean in the $80 \mathrm{~s}$ and $90 \mathrm{~s}$ : the big transition in the intermediate and deep circulations, Dynamics of Atmospheres and Oceans, 29, 365-395, 1999.

Nittis, K., Zervakis, V., Perivoliotis, L., Papadopoulos, A., and Chronis, G.: Operational monitoring and forecasting in the Aegean Sea: System Limitations and Forecasting Skill Evaluation, Marine Pollution Bulletin, 43, 7-12, 154-163, 2001.

Pinardi, N. and Flemming, N. C.: The Mediterranean Forecasting System Science Plan, EUROGOOS Publication No. 11, Southampton Oceanography Centre, Southampton, ISBN 0904175-35-9, 1998.

Press, W. H., Teukolsky, S. A., Vetterling, W. T., and Flannery, B. P.: Numerical Recipes in Fortran - The Art of Scientific Computing, 
2nd edition, Cambridge University Press, 670-674, 1992.

Robinson, A. R., Colnaraghi, M., Leslie, W. G., Artegiani, A., Hecht, A., Lazzoni, E., Michelato, A., Sansone, E., Theocharis, A., and Ünlüata, Ü.: The eastern Meditarranean general circulation: features, structures and variability, Dynamics of Atmospheres and Oceans, 15, 215-240, 1991.

Roether, W., Manca, B. B., Klein, B., Bregant, D., Georgopoulos, D., Beitzel, V., Kovacevic, V., and Luchetta, A.: Recent Changes in eastern Mediterranean Deep Waters, Science, 271, 333-335, 1996.

Soukissian, T., Chronis, G., and Nittis, K.: POSEIDON: Operational Marine Monitoring System for the Greek Seas, Sea Technology, 40, 31-37, 1999.

Theocharis, A., Balopoulos, E., Kioroglou, S., Kontoyiannis, H., and Iona, A.: A synthesis of the circulation and hydrography of the South Aegean Sea and the Straits of the Cretan Arc (March 1994-January 1995), Progress in Oceanography, 44, 469-509, 1999.

Zervakis, V., Nittis, K., Theocharis, A., and Georgopoulos, D.: The interactive relation of water column structure and mesoscale circulation in the Cretan Sea during the last decade, Ann. Geophysicae, Part II, 16, C568, 1998.

Zervakis, V., Nittis, K., Perivoliotis, L., and Tziavos, C.: A comparison of model predictions to observations of seasonal variability and circulation in the eastern Mediterranean, The Global Atmosphere and Ocean System, special issue: POSEIDON: An integrated operational oceanographic system, 8, 2-3, 141-162, 2002. 